\title{
Exergy Analysis as a Tool for Addressing Climate Change
}

\author{
Marc A. Rosen ${ }^{1 *}$ \\ ${ }^{1}$ Faculty of Engineering and Applied Science, University of Ontario Institute of Technology, Oshawa, Ontario, L1G 0C5, CANADA
}

*Corresponding Author: marc.rosen@uoit.ca

Citation: Rosen, M. A. (2021). Exergy Analysis as a Tool for Addressing Climate Change. European Journal of Sustainable Development Research, 5(2), em0148. https://doi.org/10.21601/ejosdr/9346

\section{ARTICLE INFO}

Received: 1 Oct. 2020

Accepted: 3 Oct. 2020

\begin{abstract}
Exergy is described as a tool for addressing climate change, in particular through identifying and explaining the benefits of sustainable energy, so the benefits can be appreciated by experts and non-experts alike and attained. Exergy can be used to understand climate change measures and to assess and improve energy systems. Exergy also can help better understand the benefits of utilizing sustainable energy by providing more useful and meaningful information than energy provides. Exergy clearly identifies efficiency improvements and reductions in wastes and environmental impacts attributable to sustainable energy. Exergy can also identify better than energy the environmental benefits and economics of energy technologies. Exergy should be applied by engineers and scientists, as well as decision and policy makers, involved in addressing climate change.
\end{abstract}

Keywords: exergy, climate change, environment, ecology, energy

\section{INTRODUCTION}

The relationship between energy and economics, such as the trade-offs between efficiency and cost, has almost always been important. In recent decades, the environmental impacts of energy use, such as global climate change, ozone depletion and acid rain, have become of concerns (Goldemberg et al., 1988; Hafele, 1981; Strong, 1992), and received increasing interest. Concerns have also been expressed in relation to energy about the non-sustainable nature of human activities, as highlighted by the United Nations Sustainable Development Goals (SDGs) for 2015-2030 (UN, 2015), and effort has been expended on developing methods for achieving sustainable development, including the achievement of energy sustainability. These issues are related, as increasing efficiency reduces environmental emissions while enhancing sustainability and the lives of resources.

To address climate change and to increase the use of sustainable energy, the benefits of relevant measures must be clearly understood and appreciated by experts and nonexperts, including the public, the media and decision-makers in industry and government. The use of energy as a tool for addressing climate change and measuring the benefits of sustainable energy systems can be misleading and confusing. However, the thermodynamic quantity exergy, which can be used to help address climate change and to enhance energy systems, can help better understand the potential benefits of relevant measures. Exergy can clearly identify efficiency improvements and reductions in wastes and environmental impacts. Exergy can also identify better than energy ways to improve environmental benefits and economics. Consequently, many researchers suggest that the impact of energy use on the environment, the achievement of increased efficiency, and the economics of energy systems are best addressed by considering exergy (Dincer and Rosen, 2013). As a consequence, many exergy methods have been developed, e.g., exergy analysis for improving the efficiency of energy systems, exergoeconomics for improving the economics of energy systems, and. Thus, exergy has an important role to play in addressing climate change and expanding use of sustainable energy.

This article discusses these points with the objective of demonstrating how exergy can help improve understanding and applying exergy methods for addressing climate change and expanding use of sustainable energy. The article is intended to help improve understanding and appreciation of exergy analysis by engineers and scientists as well as by industry, the public, the media and government. These groups all must have such understanding if appropriate decisions about green energy and technologies are to be made. This is particularly true of government policy, as it can be important for addressing climate change and shifting towards sustainable energy.

This paper goes on to describe exergy and to illustrate its use as a tool to improve efficiency. Next, the environmental implications are discussed of exergy, which relate to climate change and greenhouse gases as well as other environmental pollutants and impacts. Finally, the ties between exergy and economics, which are important given the interrelations 
between technical, environmental and economic issues, are described.

\section{BACKGROUND ON EXERGY ANALYSIS}

Exergy is defined as the maximum amount of work which can be produced by a system or a flow of matter or energy as it comes to equilibrium with a reference environment. Exergy is a measure of the potential of the system or flow to cause change, as a consequence of not being completely in stable equilibrium relative to the reference environment. The exergy of an energy form or a substance is a measure of its usefulness or quality, and thus is a measure of its potential to cause change. Exergy may be, or provide the basis for, an effective measure of the potential of a substance or energy form to impact the environment (Rosen, 2012).

Unlike energy, exergy is not subject to a conservation law (except for ideal, or reversible, processes). Rather exergy is consumed or destroyed, due to irreversibilities in any real process. The exergy destruction during a process is proportional to the entropy created due to irreversibilities associated with the process.

Exergy analysis is a method that uses the conservation of energy principle (embodied in the first law of thermodynamics) together with non-conservation of entropy principle (embodied in the second law) for the analysis, design and improvement of energy and other systems. The exergy method is useful for improving the efficiency energy-resource use, for it quantifies the locations, types and magnitudes of wastes and losses. In general, more meaningful efficiencies are evaluated with exergy analysis rather than energy analysis, since exergy efficiencies are always a measure of the approach to the ideal. Therefore, exergy analysis identifies the margin available to design more efficient energy systems by reducing inefficiencies. Many engineers suggest that energy systems are best evaluated using exergy analysis because it provides more insights, especially for efficiency improvement, than energy analysis. Exergy analysis and its application to many processes and systems are elucidated in numerous books (Dincer and Rosen, 2013; Edgerton, 1992; Kotas, 1995; Moran, 1989; Szargut et al., 1988) and important articles (Mahmoudi et al., 2019; Moran and Sciubba, 1994; Szargut, 1980).

In exergy analysis, the characteristics of the reference environment must be specified completely. This is commonly done by specifying the temperature, pressure and chemical composition of the reference environment. The results of exergy analyses, consequently, are relative to the specified reference environment, which in most applications is modelled after the actual local environment. The exergy of a system is zero when it is in equilibrium with the reference environment. This tie between exergy and the environment leads to some of the implications regarding environmental impact that are discussed subsequently.

\section{USING EXERGY TO REDUCE CLIMATE CHANGE AND GREENHOUSE GAS EMISSIONS}

\author{
Efficiency Improvement and Emissions Reduction in \\ Industry
}

The primary use of exergy analysis is as a methodology for understanding the behavior of and improving the efficiency of energy systems. The exergy method is useful for improving efficiency because more meaningful efficiencies are evaluated with exergy rather compared to energy, since exergy efficiencies are always a measure of the approach to the ideal.

Many examples can be used to demonstrate the use and benefits of exergy for efficiency improvement. Some are presented here. In all of these cases, exergy analysis helps identify measures to improve efficiency. These measures lead to reduced fuel use and, consequently, lower greenhouse gas emissions.

Thermal energy storage. Consider a buried thermal energy storage tank. A hot medium flows through a heat exchanger within the storage and heat is transferred into the storage. After a period of time, a cold fluid is run through the heat exchanger and heat is transferred from the storage into the cold fluid. The amount of heat recovered depends on how much heat has escaped from the storage into the surrounding soil, and how long the recovery fluid is passed through the heat exchanger. But a problem arises in evaluating the energy efficiency of this storage because the energy efficiency can be increased simply by lengthening the time that the recovery fluid is circulated. What is neglected here is the fact that the temperature at which the heat is recovered is continually decreasing towards the ambient soil temperature as the fluid circulates. Thus although the energy recovered increases as the recovery fluid continues to circulate, the exergy recovered hardly increases at all after a certain time, reflecting the fact that recovering heat at near-environmental temperatures does not make a storage more efficient thermodynamically.

Space heater. Space heating can be accomplished in many ways. For an electrical resistance space heater, almost all of the electricity that enters the unit is dissipated to heat within the space. Thus the energy efficiency is nearly $100 \%$ and there are almost no energy losses. Yet the exergy efficiency of such a device is typically less than $10 \%$, indicating that the same space heating can in theory be achieved using one-tenth of the electricity. In reality, some of these maximum savings in electricity use can be attained using a heat pump. The use of even a relatively inefficient heat pump can reduce the electricity used to achieve the same space heating by onethird. Clearly the use of energy efficiencies and losses is quite misleading for electrical heating.

Ideal heat engine. Consider a Carnot (ideal) heat engine operating between a heat source at a temperature of $600 \mathrm{~K}$ and a heat sink at $300 \mathrm{~K}$. The energy efficiency of this device is $50 \%$ (i.e., $1-300 / 600=0.5$ ). Yet a Carnot engine is ideal. Clearly, the energy efficiency is misleading as it indicates that a significant margin for improvement exists when in fact there is none. The exergy efficiency of this device is $100 \%$, properly 


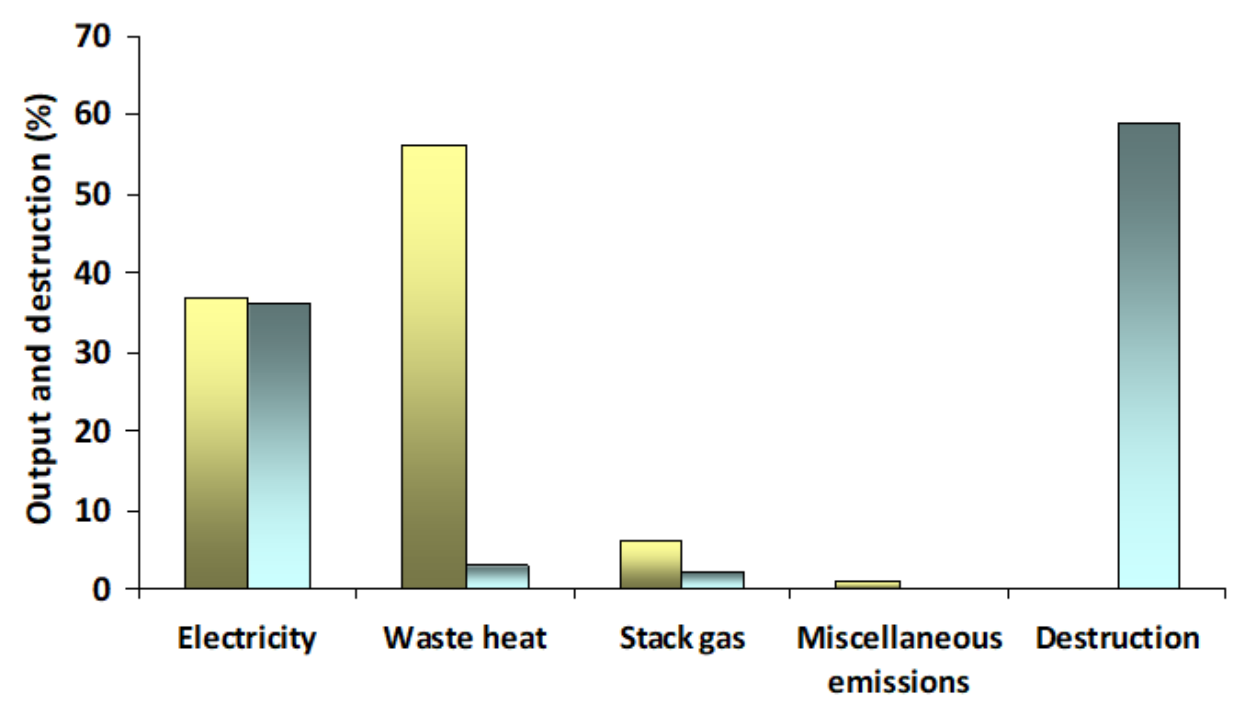

Figure 1. Energy and exergy outputs and destructions, as a percentage of total input, for the coal-fired electrical generating plant

indicating its ideal nature in a straightforward and clear manner.

Actual power plant. Consider electricity generation using a typical unit of a coal-fired power plant, which has a net electrical output of $500 \mathrm{MW}$. The unit consists of four main sections:

- Steam generator: Pulverized-coal-fired natural circulation steam generators combust coal to produce primary and reheat steam. The flue gas exits the plant via multi-flued chimneys.

- Turbine generators and transformer: Steam passes through a turbine generator, which is connected to a transformer. The turbine generator has one high-pressure cylinder, one intermediate-pressure cylinder and two low-pressure cylinders. Steam exhausted from the high-pressure cylinder is reheated in the steam generator. Several steam extractions from the turbines preheat feed water in low- and high-pressure heat exchangers and one spray-type open deaerating heat exchanger.

- Condenser: The low-pressure turbines exhaust to the condenser, where cooling water condenses the steam.

- Preheating heat exchangers and pumps: The temperature and pressure of the condensed steam are increased in a series of pumps and heat exchangers.

Breakdowns of the overall outputs of energy and exergy (and destructions for exergy) for the plant are shown in Figure 1. This information improves understanding of the thermodynamic characteristics of the plant and identify areas with significant potential for efficiency improvement, in several ways:

- The overall energy efficiency (ratio of net electrical energy output to coal energy input) is $37 \%$, and the corresponding exergy efficiency is $36 \%$.

- The steam generator is significantly more efficient on an energy basis (95\%) than on an exergy basis (50\%).
Physically, this discrepancy implies that, although most of the input energy is transferred to the preheated water, the energy is degraded as it is transferred. Most of the exergy losses in the steam generators are associated with internal destructions (mainly due to combustion and heat transfer).

- Large quantities of energy enter the condensers, of which close to $100 \%$ is rejected. A small quantity of exergy enters, of which about $25 \%$ is rejected and $75 \%$ internally destroyed.

- Energy losses in other plant devices were found to be very small (about $10 \mathrm{MW}$ total), and exergy losses were found to be moderately small (about $150 \mathrm{MW}$ total). The exergy losses are almost completely associated with internal destructions.

\section{Efficiency Improvement and Emissions Reduction in Government and Public Policy}

Facets of exergy relate to government policies, strategies and priorities in areas such as environment, energy, natural resources, industry and economic development. Governments can use exergy methods in establishing public policies in such areas to increase the resulting benefits. Some of these are now described.

Environment policies. Exergy methods provide useful tools for mitigating environmental impacts, in large part because of the links between exergy and environmental impacts and issues. For instance, since the exergy of emissions correlates with the theoretical work required to reverse environmental impact, exergy methods can help identify and quantify appropriate financial taxes and penalties for polluters. Wall (1993) proposed an exergy tax to improve resource use and decrease environmental destruction, writing "misuse of physical resources from poor understanding of concepts such as exergy, misuse of nature from ignorance of ecology." Over the last few decades, various exergy- 
environment methods have evolved, which can be integrated with government environmental policy.

Energy and natural resources policies. Exergy can provide a useful perspective for governments to establish natural resource and energy security, for a country or societies within it. For instance, exergy methods assist efforts to assess and improve the efficiencies of energy and other resources use, identifying both actual and maximum efficiencies as well as the causes and locations of losses. Despite their widespread use, energy methods often do not provide such information. By establishing upper limits, exergy methods identify and quantify targets for increased efficiency, based on high exergy losses.

Economic and industry policies. Exergy methods can be integrated with economics to address financial and economic problems in industry. This work helps identify optimal systems and processes, as well as operation levels, in industries. The same methods, however, can be used by government for extended purposes. For example, governments can use exergyeconomic methods to determine appropriate financial taxes, penalties and subsidies to motivate industry to use non-carbon energy and to be more efficient. More broadly, government can utilize and exergy exergy-economic methods to improve economic performance, by providing resources such as funding and expertise to determine how best to affect economic conditions to make aims more likely to be met, and to facilitate the adoption of exergy and exergy-economic methods.

Global, national and regional policies. Evaluations have been carried out of exergy flows through the world, countries and regions, as well as specific parts of their economies. For instance, global exergy efficiencies have been examined, while exergy analyses have been reported for such countries as Canada, the United States, Japan, Italy, Sweden, Turkey, the U.K. and others. Such analyses of regional and national energy utilization have been comparatively reviewed by Rosen (2013). These efforts mainly focus on understanding the true efficiency of energy and resource use in these jurisdictions and thus provide useful information to multi-national, national and regional governments for policy making. Such efforts need to be extended so as to enhance the benefits of exergy methods, via government policy.

Despite the potential benefits of exergy methods, their implications are often not followed, usually unknowingly. For instance, government R\&D funding is often provided to areas of the economy where the energy losses, even if exergy losses low, despite the fact that the greatest margin for improvement is in those areas exhibiting high exergy losses (e.g., space heating has an exergy efficiency below $10 \%$ although its high energy efficiency often exceeds 80\%). At the government level, the effects of such resource misallocations can be significant. For instance, a study for Ontario, Canada of government investment in $R \& D$ and the energy and exergy losses of the processes funded showed a direct relation between funding level and energy losses and an inverse relation between funding level and exergy losses. These observations suggest funding misallocation since the greatest impact is achieved with limited public funds and resources is in areas with the largest margins for efficiency improvement, or largest potential benefits. Thus the largest research funding allocation should be to processes with the largest exergy losses (unless other factors dictate otherwise).

Related investigations of a broader nature have also been reported, including the use of exergy in government policy (Dincer and Rosen, 2013), its importance in relation to democracy and modern society dilemmas (Wall, 1993), and exergy aspects of self-sustainability for societies (Sciubba, 1995).

\section{EXERGY, ENVIRONMENT AND SUSTAINABILITY}

Although energy and resources help meet human needs and improve living standards and quality of life, they generally lead to environment impacts. For instance the United Nations (Strong, 1992) indicates that effective strategies to protect the atmosphere must address the energy sector by shifting to environmentally benign energy systems and increasing efficiency. The UN Sustainable Development Goals (20152030) reinforce and expand on these ideas (Rosen, 2017b; UN, 2015). In particular, carbon dioxide emissions mitigation can be achieved by introducing sustainable and renewable energy sources, reducing the fossil fuel portion of the energy mix and increasing efficiency. Renewable forms of energy include bioenergy (Rosen, 2017c) and geothermal energy (Rosen and Koohi-Fayegh, 2017).

\section{Exergy and the Environment}

Environmental measures can reduce impacts like climate change by lowering resource and energy losses. Such actions raise exergy efficiency and reduce exergy losses (waste exergy emissions and destructions).

Exergy can help fundamentally in understanding and reducing environmental impact. Understanding the relations between exergy and the environment helps in identifying underlying fundamental patterns and forces affecting environmental changes and in addressing environmental damage. For example, Tribus and McIrvine (1971) suggest exergy analyses of natural processes on the earth can form a foundation for ecologically sound planning by quantifying disturbances from large-scale changes. Also, one link between environmental impact and exergy stems from the latter being a measure of the departure of the state of a system from that of the environment (Edgerton, 1992; Szargut, 1980; Rosen, 2012). The exergy of a system, which depends on the states of both the system and the environment, is zero only when the system and its environment are in equilibrium.

Other examinations of exergy and the environment have been undertaken. Rosen and Dincer (1997) investigate relations between exergy and environmental impact, while Sciubba (1999) examines exergy as a direct measure of environmental impact and Creyts and Carey (1997) employ extended exergy analysis for the environmental assessment of industrial processes. Rosen and Dincer (1999) describe the exergy of waste emissions and Crane et al. (1992) apply those concepts to energy conversion technologies. Ayres et al. (1998) discuss relations between exergy, waste accounting, and lifecycle analysis, while Connelly and Koshland (1997) utilize an 
exergy-based measure of degradation to advance industrial ecology. Tyagi et al. (2005) develop optimal criteria based on an ecological function using exergy for a modified Brayton cycle.

In recent years, activity regarding improving understanding of the relation between exergy and the environment and its role has expanded (Nižetić and Papadopoulos, 2018). Kılkış and Kılkış (2017) propose new exergy metrics for energy, the environment, and the economy and apply them in optimization. Exergoeconoenvironmental analysis is considered for improving understanding of energy systems (Aghbashlo and Rosen, 2019) and for dveloping thermodynamically, economically, and environmentally sound energy conversion systems (Aghbashlo and Rosen, 2018). Furthermore, Nwodo et al. (2020) have recently reviewed exergetic life cycle assessment.

Research on the relation between exergy and ecology has also received increased attention in recent years. Valero et al. (2017) describe the theory of exergy cost and thermoecological cost, while Valero et al. (2018) assess the exergy degradation of natural capital and propose a thermoecological-cost methodology. Meanwhile, Stanek and Czarnowska (2018) consider thermo-ecological cost for quantifying the exergy and ecology connection, and Sciubba (2019) has reviewed exergy-based ecological indicators. Vihervaara et al. (2019) consider eco-exergy as an indicator of ecosystem complexity, and He et al. (2019) use exergy as a thermodynamic index for system-level ecological risk assessment of contaminates. Issues regarding the relation between exergy and ecology have also been examined. For instance, Nielsen (2019) discusses issues arising when shifting the concept of exergy among ecological levels and domains.

Some studies have focused on climate change. For example, Berthiaume and Rosen (2017) examine limits imposed by the second law of thermodynamics on reducing greenhouse gas emissions, while Hernandez and Cullen (2019) describe exergy as a universal metric for measuring resource efficiency to address industrial decarbonisation. Veiga and Romanelli (2020) examine the mitigation of greenhouse gas emissions using exergy, and Zhang and Reistad (1998) analyze energy conversion systems with exergy methods, including material and global warming aspects. Khajehpour et al. (2019) consider responsibility allocation of climate change based on exergy. Arango-Miranda et al. (2018) investigate the role of exergy in carbon dioxide emissions, energy consumption and economic growth, while Wu and Wang (2020) explore avoidable carbon emissions by reducing exergy destruction based on advanced exergy analysis.

The present author previously introduced three relationships between exergy and environmental impact (Rosen and Dincer, 1997) that can be instructive:

Order destruction. Order destruction is a form of environmental damage, and perhaps the distress of people by a polluted landscape compared to a clean one suggests exergy and order in the environment may relate to human values. Irrespective of human values, as entropy is fundamentally a measure of disorder, exergy is a measure of order. A system of low exergy is more disordered or chaotic than one of high exergy. The exergy difference of the two systems is a measure of (i) the exergy (and order) destroyed order is lost, and (ii) the minimum work required to reorder the disordered system (i.e., to clean up). In reality, more than this minimum work, which only applies if a reversible clean-up process is employed, is required. For example, an atmosphere with anthropogenic carbon dioxide emissions distributed throughout it has lower exergy than a large container with the anthropogenic carbon dioxide constrained. The exergy difference of the two systems is a measure of (i) the exergy (and order) destroyed when the anthropogenic carbon dioxide is emitted into and diffuses throughout the atmosphere, and (ii) the minimum work required to extract the carbon dioxide and place it into a container and at the same time to return the state of the environment (i.e., capture and sequester the carbon dioxide). In reality, the exergy represents the minimum work required if a reversible gas separation process is employed, and in actuality more than this work is needed.

Resource degradation. Resource degradation is a form of environmental damage. Kestin (1980) defines a resource as a material, found in nature or created artificially, which is in a state of disequilibrium with the environment, and notes that resources have exergy as a consequence of this disequilibrium. Resources are valued for their reactivity (like a fuel) and/or composition (like a purified ore). Processes exist to increase the value (and exergy) of resources by purification. The environmental impact of resource degradation can be mitigated by increasing efficiency to reduce the exergy necessary for a process and the corresponding environmental damage, and using external exergy resources instead of degrading natural resources like fossil fuels, which is possible since the earth is an open system subject to a net influx of exergy. For example, the exergy (or order) delivered with solar radiation is valued, since all the energy received from the sun is ultimately re-radiated to the universe.

Waste emission. By not being in stable equilibrium with the environment, the exergy of wastes represents a potential to cause change, which may manifest itself as a potential for environmental damage. Usually, emitted exergy causes a change which is damaging to the environment. Exergy emissions to the environment can also affect the net input of exergy via solar radiation to the earth (e.g., emissions of carbon dioxide and other greenhouse gases are raising the atmospheric $\mathrm{CO}_{2}$ concentration). Reistad (1970) developed an air-pollution rating he claimed was preferable to the mainly empirical ratings then in use, by determining the air-pollution cost for a fuel as either (i) the cost to remove the pollutant or (ii) the cost to society of the pollution in the form of a tax.

The relationships between exergy and environment are illustrated by revisiting the actual power plant in Section "Efficiency Improvement and Emissions Reduction in Industry".

- Order destruction. Order destruction occurs during the exergy destroying conversion of a fuel to less ordered stack gases and solid wastes, and as wastes are emitted to the environment, allowing the products of combustion to diffuse and interact throughout the environment unconstrained.

- Resource degradation. A fossil fuel, a finite resource, is degraded as electricity is generated. Although some 
Order destruction

Resource degradation

Waste exergy emission

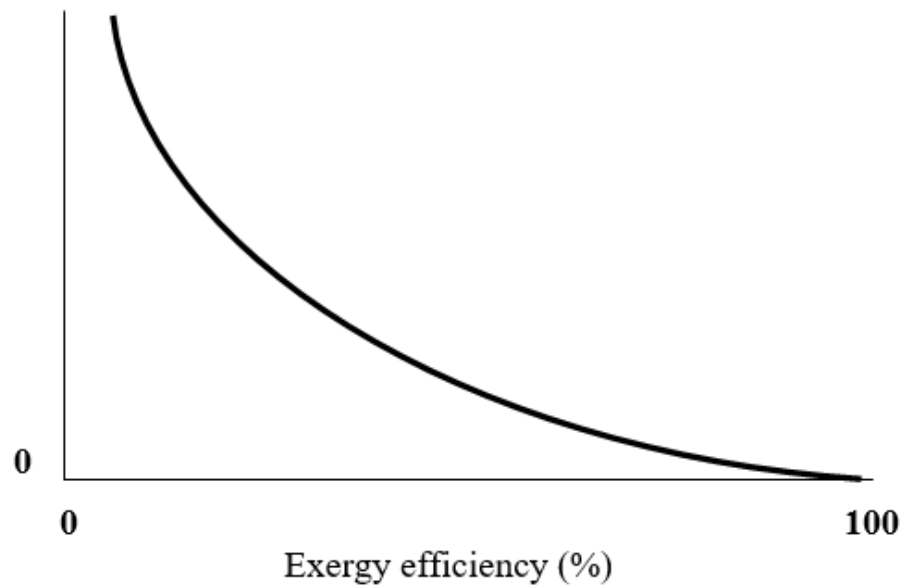

Figure 2. Conceptual effect of process exergy efficiency on associated environmental impact in terms of order destruction, resource degradation, and waste exergy emission

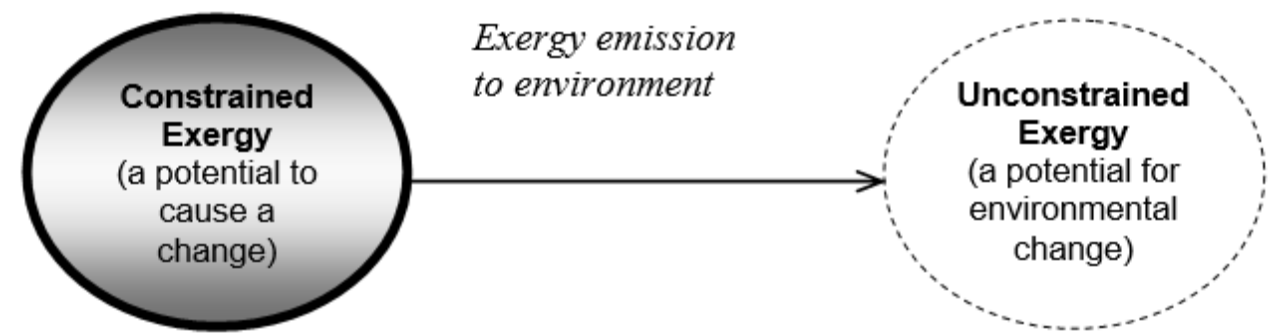

Figure 3. Comparison of constrained exergy (e.g., a resource) and unconstrained exergy (a potential for environmental damage)

resource degradation is unavoidable for a real process, increased exergy efficiency can reduce the degradation. In the extreme, if actual power plant in Section "Efficiency Improvement and Emissions Reduction in Industry" became thermodynamically ideal, i.e., the exergy efficiency rose to $100 \%$ from $37 \%$, fossil fuel use would decrease by over $60 \%$ as would related emissions.

- Waste emission. Waste exergy is emitted from the plant with stack gas and solid combustion wastes, as well as with the waste heat from the condenser and miscellaneous sources, and these emissions represent varying degrees of potential environmental impact. The exergy insights regarding environmental-impact potential of these phenomena is not fully understood, although societal concerns have long existed regarding releases of harmful chemical constituents with stack gases and thermal pollution in local water bodies.

The decrease in the environmental impact of a process, in terms of these measures, as the process exergy efficiency increases is illustrated approximately in Figure 2. Note that, although exergy in the environment in the form of resources is of value while exergy in the environment in the form of emissions is harmful, it is the constrained nature of exergy in resources that differentiates the ideas, as illustrated in Figure 3. Unconstrained emissions of exergy can impact the environment in an uncontrolled manner.

\section{Exergy and Sustainability}

The United Nations Sustainable Development Goals for 2015-2030 (UN, 2015) spell out a broad view for moving the world towards sustainability, and energy is a key aspect of many of the 17 goals (Rosen, 2017b). Sustainability requires sustainable energy resources be used, both cleanly and efficiently (Rosen, 2017a). Exergy methods aid in improving efficiency, thereby enhancing the benefits derived from resources while mitigating problems like environmental impact and lengthening the lifetimes of finite resources. When striving for sustainability, one seeks energy resources that cause no environmental impact. This probably involves using energy resources that lead to no environmental waste emissions or only waste emissions having no environmental impact, the latter relevant when environmental emissions are inert or in equilibrium (thermal, mechanical and chemical) with the environment. In actuality, resource use entails some environmental impact, and increased efficiency can offset some of the limitations imposed on sustainability by environmental emissions. Even if inexpensive and widely available, it will be advantageous to use energy resources efficiently to reduce the corresponding resource needs (energy, material, etc.) to build the relevant systems and environmental impacts.

Exergy methods can help improve sustainability. This can be seen in Figure 4, an expanded version of Figure 2 showing qualitatively how sustainability increases and environmental impact decreases with increasing exergy efficiency. As exergy efficiency approaches $100 \%$, sustainability approaches infinity since the process approaches reversibility, while environmental impact approaches zero because exergy is converted from one form to another without any loss., Sustainability approaches $0 \%$ as exergy efficiency approaches $0 \%$ since exergy resources are used to accomplish nothing, while environmental impact approaches infinity because increasing resources must be used and increasing exergy 


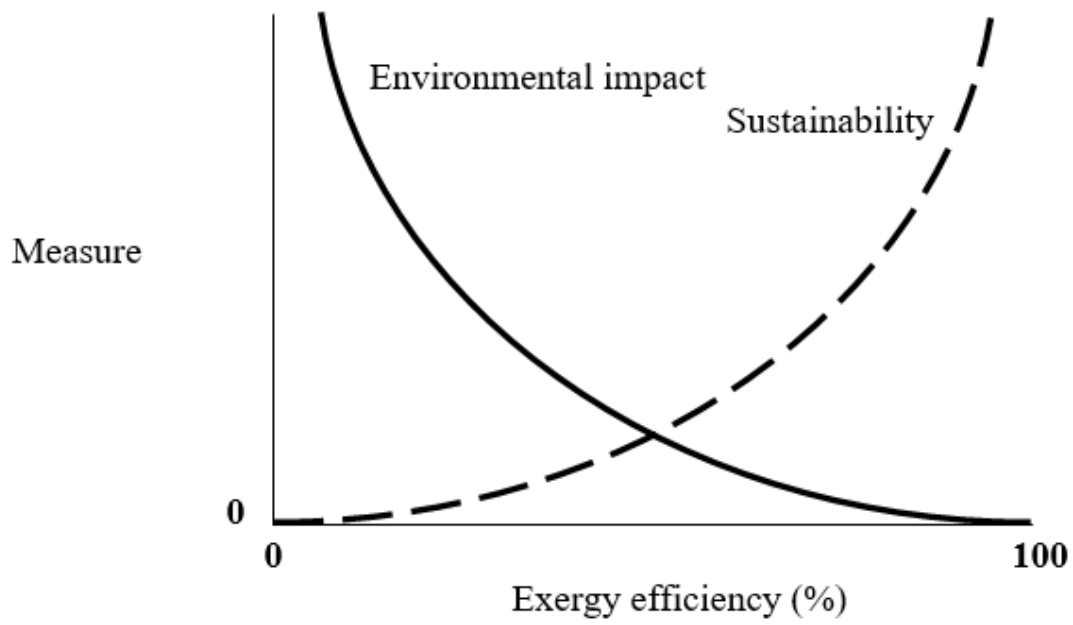

Figure 4. Qualitative depiction of relation of environmental impact and sustainability with exergy efficiency

wastes are emitted, for a fixed service. Some point out directly that exergy analysis is an element of attaining sustainable development (Cornelissen, 1997), noting that energy can not be "lost" as it is conserved while exergy can be lost due to irreversibilities. Consequently, exergy losses, especially from using non-renewable energy forms, should be reduced to attain sustainability, and environmental impacts of emissions and resource depletion can be expressed in terms of a physically based exergy indicator.

Others have examined relations between exergy and sustainability. Nielsen (2020) describes an exergy-based approach sustainable development indicators, while Lucia and Grisolia (2019) consider exergy inefficiency as an indicator for sustainable development analysis. Whiting et al. (2017) describe the use of exergy to evaluate the sustainability of fossil fuels and non-fuel mineral depletion and Zhang et al. (2018) seek to improve understanding of the sustainability of fuel from the viewpoint of exergy. Stanek et al. (2019) describe the use of exergy as a measure of sustainability through thermo-ecology. Hacatoglu et al. (2015) use exergy as an element of a method to assess the environmental impact and sustainability of energy systems. Generally, exergy and its application for sustainable environment has received much interest recently (Aziz, 2019).

\section{EXERGY AND ECONOMICS}

Economic issues are important in assessing and developing systems. In designing systems, technical disciplines (especially thermodynamics) are combined with economics to achieve preferred and optimal systems. For energy system, costs are usually based on energy, although many suggest costs are better distributed among outputs based on exergy (Rosen, 2011; Tsatsaronis, 1994).

Numerous exergy-economic methods have been developed, e.g., exergoeconomics, thermoeconomics and second-law costing. El-Sayed and Gaggioli (1989) critically reviewed costing methods using exergy, while Mazur (2005) describe fuzzy thermoeconomic optimization. Jaber et al. (2004) even use exergy in describing price-driven economic order systems from a thermodynamic perspective. Tsatsaronis (1987) identifies four main types of methodologies corresponding to the basis of the technique being exergyeconomic cost accounting, exergy-economic calculus analysis, exergy-economic similarity number, or product/cost efficiency diagrams. Exergy-economic methods generally recognize exergy rather than energy as the commodity of value in a system, and assign costs and/or prices to exergy variables, thereby appropriately allocating economic resources to optimize system design and operation and attaining the highest profitability.

One reason costs are better distributed among outputs when based on exergy is that exergy often is a consistent measure of economic value, while this is true only sometimes for energy. This can be illustrated by revisiting the actual power plant in Section "Efficiency Improvement and Emissions Reduction in Industry" so as to provide possible general relations between thermodynamic losses and capital costs (Rosen and Dincer, 2003). By examining economic and thermodynamic data for mature devices, correlations were shown between capital costs and some thermodynamic losses for devices. Such correlations suggest that designers incorporate exergy information in designs indirectly, probably unknowingly. For the actual power plant in Section "Efficiency Improvement and Emissions Reduction in Industry", the following were observed:

- For the energy and exergy thermodynamic losses, a significant parameter is the ratio of thermodynamic loss rate to capital cost. Further, a systematic correlation appears to exist between exergy loss rate and capital cost, but not between energy loss rate and capital cost.

- Devices in actual power plants appear to conform approximately to a particular value of the thermodynamic-loss-rate-to-capital-cost ratio based on exergy loss, reflecting an appropriate trade-off between exergy losses and capital costs, i.e., one that applies in successful plant designs.

\section{CONCLUSIONS}

The benefits of using exergy as a tool for addressing climate change, in particular through identifying and 
explaining the benefits of sustainable energy, has been demonstrated. It is concluded that the concepts encompassing exergy have a significant role to play in addressing climate change and increasing sustainable energy use. Exergy clearly identifies efficiency improvements and reductions in wastes and environmental impacts attributable to sustainable energy, and enhances understanding of environmental benefits and economics. Exergy should prove useful in such activities to engineers and scientists, as well as decision and policy makers in addressing climate change.

\section{ACKNOWLEDGEMENTS}

The support for this work provided by the Natural Sciences and Engineering Research Council of Canada is gratefully acknowledged.

\section{REFERENCES}

Aghbashlo, M. and Rosen, M. A. (2018). Exergoeconoenvironmental Analysis as a New Concept for Developing Thermodynamically, Economically, and Environmentally Sound Energy Conversion Systems. Journal of Cleaner Production, 187, 190-204. https://doi.org/10.1016/j.jclepro.2018.03.214

Aghbashlo, M. and Rosen, M. A. (2019). Towards a better understanding of energy systems using emergy-based exergoeconoenvironmental analysis. International Journal of Exergy, 28(3), 209-228. https://doi.org/10.1504/ IJEX.2019.10020030

Arango-Miranda, R., Hausler, R., Romero-Lopez, R., Glaus, M. and Ibarra-Zavaleta, S. P. (2018). Carbon dioxide emissions, energy consumption and economic growth: A comparative empirical study of selected developed and developing countries. "The role of exergy". Energies, 11, 2668. https://doi.org/10.3390/en11102668

Ayres, R. U., Ayres, L. W. and Martinas, K. (1998). Exergy, waste accounting, and life-cycle analysis. Energy, 23, 355-363. https://doi.org/10.1016/S0360-5442(97)00076-5

Aziz, M. (Ed.) (2019). Exergy and Its Application: Toward Green Energy Production and Sustainable Environment. IntechOpen: London. https://doi.org/10.5772/intechopen. 77461

Berthiaume, R. and Rosen, M. A. (2017). Limits imposed by the second law of thermodynamics on reducing greenhouse gas emissions to the atmosphere. Research Journal of Environmental Sciences, 11(1), 18-28. https://doi.org/ 10.3923/rjes.2017.18.28

Connelly, L. and Koshland, C. P. (1997). Two aspects of consumption: using an exergy-based measure of degradation to advance the theory and implementation of industrial ecology. Resources, Conservation and Recycling, 19, 199-217. https://doi.org/10.1016/S09213449(96)01180-9

Cornelissen, R. L. (1997). Thermodynamics and Sustainable Development (Ph.D. Thesis), University of Twente, the Netherlands.
Crane, P., Scott, D. S. and Rosen, M. A. (1992). Comparison of exergy of emissions from two energy conversion technologies, considering potential for environmental impact. Int. J. Hydrogen Energy, 17, 345-350. https://doi.org/10.1016/0360-3199(92)90171-R

Creyts, J. C. and Carey, V. P. (1997). Use of extended exergy analysis as a tool for assessment of the environmental impact of industrial processes. Proc. ASME Advanced Energy Systems Division, AES-Vol 37, 129-137.

Dincer, I. and Rosen, M. A. (2013). Exergy: Energy, Environment and Sustainable Development (2nd ed.). Oxford, UK: Elsevier.

Edgerton, R. H. (1992). Available Energy and Environmental Economics. Toronto: D.C. Heath.

El-Sayed, Y. M. and Gaggioli, R. A. (1989). A critical review of second law costing methods: Parts I and II. ASME J. Energy Resources Technology, 111, 1-15. https://doi.org/10.1115/ 1.3231396

Goldemberg, J., Johansson, T. B., Reddy, A. K. N. and Williams, R. H. (1988). Energy for a Sustainable World. New York: Wiley.

Hacatoglu, K., Dincer, I. and Rosen, M. A. (2015). A new model to assess the environmental impact and sustainability of energy systems. Journal of Cleaner Production, 103, 211218. https://doi.org/10.1016/j.jclepro.2014.06.050

Hafele, W. (1981). Energy in a Finite World: A Global Systems Analysis. Toronto: Ballinger.

He, W., Kong, X., Qin, N., He, Q., Liu, W.X., Bai, Z., Wang, Y. and $\mathrm{Xu}, \mathrm{F}$. (2019). Combining species sensitivity distribution (SSD) model and thermodynamic index (exergy) for system-level ecological risk assessment of contaminates in aquatic ecosystems. Environment International, 133(Part B), 105275. https://doi.org/10.1016/ j.envint.2019.105275

Hernandez, A. G. and Cullen, J. M. (2019). Exergy: A universal metric for measuring resource efficiency to address industrial decarbonisation. Sustainable Production and Consumption, 20, 151-164. https://doi.org/10.1016/j.spc. 2019.05.006

Jaber, M. Y., Nuwayhid, R. Y. and Rosen, M. A. (2004). Pricedriven economic order systems from a thermodynamic point of view. Int. J. Production Research, 42, 5167-5184. https://doi.org/10.1080/00207540412331281971

Kestin, J. (1980). Availability: the concept and associated terminology. Energy, 5, 679-692. https://doi.org/10.1016/ 0360-5442(80)90088-2

Khajehpour, H., Saboohi, Y. and Tsatsaronis, G. (2019). Exergy-based responsibility allocation of climate change. In: Leal Filho, W., Leal-Arcas, R. (Eds), University Initiatives in Climate Change Mitigation and Adaptation. Cham, Switzerland: Springer. https://doi.org/10.1007/978-3-31989590-1_17

Kılkış, B. and Kılkış, Ş. (2017). New exergy metrics for energy, environment, and economy nexus and optimum design model for nearly-zero exergy airport (nZEXAP) systems. Energy, 140(Part 2), 1329-1349. https://doi.org/10.1016/ j.energy.2017.04.129 
Kotas, T. J. (1995). The Exergy Method of Thermal Plant Analysis (Reprint Ed.), Krieger, Malabar, Florida.

Lucia, U. and Grisolia, G. (2019). Exergy inefficiency: An indicator for sustainable development analysis. Energy Reports, 5, 62-69. https://doi.org/10.1016/j.egyr. 2018.12.001

Mahmoudi, S. M. S., Sarabchi, N., Yari, M. and Rosen, M. A. (2019). Exergy and Exergoeconomic Analyses of a Combined Power Producing System Including a Proton Exchange Membrane Fuel Cell and an Organic Rankine Cycle. Sustainability, 11(12), 3264. https://doi.org/ 10.3390/su11123264

Mazur, V. A. (2005). Fuzzy thermoeconomic optimization. Int. J. Exergy, 2, 1-13. https://doi.org/10.1504/IJEX.2005. 006429

Moran, M. J. (1989). Availability Analysis: A Guide to Efficient Energy Use (Revised Ed.), ASME, New York.

Moran, M. J. and Sciubba, E. (1994). Exergy analysis: principles and practice, J. Engineering for Gas Turbines and Power, 116, 285-290. https://doi.org/10.1115/1.2906818

Nielsen, S. N. (2019). Reductions in ecology and thermodynamics. On the problems arising when shifting the concept of exergy to other hierarchical levels and domains. Ecological Indicators, 100, 118-134. https://doi.org/10.1016/j.ecolind.2018.04.062

Nielsen, S. N. (2020). Sustainable Development Indicators: An Exergy-Based Approach. Boca Raton, FL: CRC Press. https://doi.org/10.1201/9780429289583

Nižetić, S. and Papadopoulos, A. (Eds.). (2018). The Role of Exergy in Energy and the Environment. Cham, Switzerland: Springer. https://doi.org/10.1007/978-3-319-89845-2

Nwodo, M. N. and Anumba, C. J. (2020). Exergetic life cycle assessment: A review. Energies, 13, 2684. https://doi.org/10.3390/en13112684

Reistad, G. M. (1970). Availability: Concepts and Applications (Ph.D. dissertation), Univ. of Wisconsin, Madison.

Rosen, M. A. (2011). Economics and Exergy: An Enhanced Approach to Energy Economics. Hauppauge, NY: Nova Science Publishers.

Rosen, M. A. (2012). Environment, Ecology and Exergy: Enhanced Approaches to Environmental and Ecological Management. Hauppauge, NY: Nova Science Publishers.

Rosen, M. A. (2013). Using exergy to assess regional and national energy utilization: A comparative review. Arabian Journal for Science and Engineering, 38(2), 251-261. https://doi.org/10.1007/s13369-012-0440-x

Rosen, M. A. (2017a). Sustainable development: A vital quest. European Journal of Sustainable Development Research, 1(1), 2. https://doi.org/10.20897/ejosdr.201702

Rosen, M. A. (2017b). How Can We Achieve the UN Sustainable Development Goals? European Journal of Sustainable Development Research, 1(2), 06. https://doi.org/10.20897/ ejosdr.201706

Rosen, M. A. (2017c). Bioenergy and energy sustainability. J. Fundamentals of Renewable Energy and Applications, 7(7), 25.
Rosen, M. A. and Dincer, I. (1997). On exergy and environmental impact. Int. J. Energy Res., 21, 643-654. https://doi.org/10.1002/(SICI)1099-

114X(19970610)21:7<643::AID-ER284>3.0.CO;2-I

Rosen, M. A. and Dincer, I. (1999). Exergy analysis of waste emissions. Int. J Energy Res., 23, 1153-1163. https://doi.org/10.1002/(SICI)1099114X(19991025)23:13<1153::AID-ER545>3.0.CO;2-Y

Rosen, M. A. and Dincer, I. (2003). Thermoeconomic analysis of power plants: an application to a coal-fired electrical generating station. Energy Conversion and Management, 44, 2743-2761. https://doi.org/10.1016/S0196-8904(03)000475

Rosen, M. A. and Koohi-Fayegh, S. (2017). Geothermal Energy: Sustainable Heating and Cooling Using the Ground. London: Wiley. https://doi.org/10.1002/9781119181002

Sciubba, E. (1999). Exergy as a direct measure of environmental impact. Proc. ASME Advanced Energy Systems Division, AES-Vol. 39, 573-581.

Sciubba, E. (2005). Exergo-economics: Thermodynamic foundation for a more rational resource use. International Journal of Energy Research, 29, 613-636. https://doi.org/ 10.1002/er.1096

Sciubba, E. (2019). Exergy-based ecological indicators: From Thermo-Economics to cumulative exergy consumption to Thermo-Ecological Cost and Extended Exergy Accounting. Energy, 168, 462-476. https://doi.org/10.1016/j.energy. 2018.11.101

Stanek, W. and Czarnowska, L. (2018). Thermo-ecological cost: Szargut's proposal on exergy and ecology connection. Energy, 165(Part B), 1050-1059. https://doi.org/10.1016/ j.energy.2018.10.040

Stanek, W., Gladysz, P., Czarnowska, L. and Simla, T. (2019). Thermo-ecology: Exergy as a Measure of Sustainability. Elsevier, Oxford, UK.

Strong, M. F. (1992). Energy, environment and development, Energy Policy, 20, 490-494. https://doi.org/10.1016/03014215(92)90014-S

Szargut, J. (1980). International progress in second law analysis, Energy, 5, 709-718. https://doi.org/10.1016/03605442(80)90090-0

Szargut, J., Morris, D. R. and Steward, F. R. (1988). Exergy Analysis of Thermal, Chemical and Metallurgical Processes. New York: Hemisphere.

Tribus, M. and McIrivne, E. C. (1971). Energy and information. Sci. Am., 225(3), 179-188. https://doi.org/10.1038/ scientificamerican0971-179

Tsatsaronis, G. (1987). A review of exergoeconomic methodologies. In Moran, M.J., Sciubba, E. (Eds.), Second Law Analysis of Thermal Systems (pp. 81-87), ASME, New York.

Tsatsaronis, G. (Ed.) (1994). Invited papers on exergoeconomics. Energy-The Int. Journal, 19, 279-381. 
Tyagi, S. K., Chen, J. and Kaushik, S. C. (2005). Optimal criteria based on the ecological function of an irreversible intercooled regenerative modified Brayton cycle. Int. J. Exergy, 2, 90-107. https://doi.org/10.1504/IJEX.2005. 006435

UN (2015). Transforming our World: The 2030 Agenda for Sustainable Development. Report A/RES/70/1, United Nations, 2015. Available at: https://sustainabledevelop ment.un.org/post2015/transformingourworld/publication

Valero, A., Usón, S., Torres, C. and Stanek, W. (2017). Theory of exergy cost and thermo-ecological cost. In: Stanek W. (Ed.), Thermodynamics for Sustainable Management of Natural Resources (pp. 167-202, Chapter 7). Springer, Cham. https://doi.org/10.1007/978-3-319-48649-9_7

Valero, A., Valero, A. and Stanek, W. (2018). Assessing the exergy degradation of the natural capital: From Szargut's updated reference environment to the new thermoecological-cost methodology. Energy, 163, 11401149. https://doi.org/10.1016/j.energy.2018.08.091

Veiga, J. P. S. and Romanelli, T. L. (2020). Mitigation of greenhouse gas emissions using exergy. Journal of Cleaner Production, 260, 121092. https://doi.org/10.1016/j.jclepro. 2020.121092
Vihervaara, P., Franzese, P. P. and Buonocore, E. (2019). Information, energy, and eco-exergy as indicators of ecosystem complexity. Ecological Modelling 395:23-27. https://doi.org/10.1016/j.ecolmodel.2019.01.010

Wall, G. (1993). Exergy, ecology and democracy-concepts of a vital society. Proc. International Conference on Energy Systems and Ecology (pp. 111-121), Cracow, Poland.

Whiting, K., Carmona, L. G. and Sousa, T. (2017). A review of the use of exergy to evaluate the sustainability of fossil fuels and non-fuel mineral depletion. Renewable and Sustainable Energy Reviews, 76, 202-211. https://doi.org/10.1016/j.rser.2017.03.059

Wu, J. and Wang, N. (2020). Exploring avoidable carbon emissions by reducing exergy destruction based on advanced exergy analysis: A case study. Energy, 206, 118246. https://doi.org/10.1016/j.energy.2020.118246

Zhang, M. and Reistad, G. M. (1998). Analysis of energy conversion systems, including material and global warming aspects. Int. J. Heating, Ventilating, Air-Cond. and Refrigerating Research, 1, 45-65. https://doi.org/10.1080/ 10789669.1998.10391390

Zhang, Y., Zhao, W., Li, B. and Li, H. (2018). Understanding the sustainability of fuel from the viewpoint of exergy. European Journal of Sustainable Development Research, 2(1), 09. https://doi.org/10.20897/ejosdr/76935 